\title{
Investigation on optical and physico-chemical properties of LPCVD $\mathrm{SiO}_{x} \mathrm{~N}_{\mathrm{y}}$ thin films
}

\author{
Bessem Kaghouche $^{1}$, Farida Mansour ${ }^{1}$, Christine Molliet ${ }^{2,3}$, Bernard Rousset ${ }^{2,3}$ and Pierre Temple- \\ Boyer $^{2,3}$ \\ ${ }^{1}$ LEMEAMED Laboratory, Electronics Department, Constantine 1 University, 25000 Constantine, \\ Algeria \\ ${ }^{2}$ CNRS, LAAS, 7 avenue du colonel Roche, F-31400 Toulouse, France \\ ${ }^{3}$ Université de Toulouse, UPS, LAAS, F-31400 Toulouse, France
}

Corresponding author: b.kaghouche@gmail.com

\begin{abstract}
In this work, the correlation between BEMA model and FTIR analysis was employed to investigate the chemical composition of silicon oxynitride $\left(\mathrm{SiO}_{\mathrm{x}} \mathrm{N}_{\mathrm{y}}\right)$ films deposited by low pressure chemical vapour deposition (LPCVD) technique at temperature of $850^{\circ} \mathrm{C}$ from nitrous oxide $\mathrm{N}_{2} \mathrm{O}$, ammonia $\mathrm{NH}_{3}$ and dichlorosilane $\mathrm{SiH}_{2} \mathrm{Cl}_{2}$. Different stoichiometries were obtained for different values of relative gas flow ratio $\mathrm{NH}_{3} / \mathrm{N}_{2} \mathrm{O}$ while keeping the $\mathrm{SiH}_{2} \mathrm{Cl}_{2}$ flow constant. The optical properties were studied using spectroscopic ellipsometry. Apart from films thickness, their refractive index as well as their $\mathrm{SiO}_{2}$ and $\mathrm{Si}_{3} \mathrm{~N}_{4}$ volume fractions were deduced using the Bruggeman effective medium approximation (BEMA) model. It was found that the refractive index increases from 1.45 to 1.60 with increasing nitrogen incorporation. The Fourier Transform Infrared spectroscopy was carried out to study the evolution of chemical bonding of LPCVD $\mathrm{SiO}_{\mathrm{x}} \mathrm{N}_{\mathrm{y}}$ films. In order to improve the qualitative analysis of their $\mathrm{Si}-\mathrm{N}$ and $\mathrm{Si}-\mathrm{O}$ vibrational modes, a correlation between Fourier transform infrared and spectroscopic ellipsometry measurements was established. A shift of infrared peaks position with the increase of relative gas flow ratio is observed. Furthermore, the calculated areas of absorption bands were used to estimate the $\mathrm{SiO}_{\mathrm{x}} \mathrm{N}_{\mathrm{y}}$ stoichiometry. This quantitative analysis was proved with an adequate method in the literature. We found a decrease of $\mathrm{x}$ values from 1.94 to 1.26 and an increase of $\mathrm{y}$ from 0.04 to 0.49 , when the $\mathrm{NH}_{3} / \mathrm{N}_{2} \mathrm{O}$ gas flow ratio increases. This behavior was explained by the increase of nitrogen content as well as the decrease of oxygen content in the $\mathrm{SiO}_{\mathrm{x}} \mathrm{N}_{\mathrm{y}}$ film.
\end{abstract}

\section{Introduction}

Silicon oxynitride has been widely used in microelectronics and optoelectronics industry as thin gate dielectrics for MOS devices, passivating coatings, waveguides, membranes in 
microsensors and solar cells [1-4]. Indeed, they exhibit excellent control of refractive index over a wide range $(n=1.45-2.02)$, low absorbance, resistance to oxidation and low mechanical stress [3, 5-7]. The stoichiometry of these materials depends strongly on the deposition method and conditions such as precursor gases, deposition temperature and pressure. They can be deposited by different methods such as low pressure chemical vapour deposition (LPCVD) [5,8], plasma-enhanced chemical vapour deposition (PECVD) [1,3,7,9], ion-assisted deposition and reactive sputtering [2]. According to all these methods, different properties can be obtained. As a result, further investigation of optical and physico-chemical characteristics remains crucial.

During several years, many studies have been performed to deduce the optical properties of $\mathrm{SiO}_{\mathrm{x}} \mathrm{N}_{\mathrm{y}}$ films with the spectroscopic ellipsometry (SE) measurements using Bruggeman Effective Medium Approximation (BEMA) [10-14]. Indeed, this model assumes that the $\mathrm{SiO}_{\mathrm{x}} \mathrm{N}_{\mathrm{y}}$ material is similar to a random mixture, at the microscale, of two homogeneous phases: $\mathrm{SiO}_{2}$ and $\mathrm{Si}_{3} \mathrm{~N}_{4}[12,13]$. However, the Fourier Transform Infrared (FTIR) analysis shows that the $\mathrm{SiO}_{x} \mathrm{~N}_{\mathrm{y}}$ films are a combination of $\mathrm{Si}-\mathrm{O}$ and $\mathrm{Si}-\mathrm{N}$ bonds $[3,7,15]$. The works reported in the literature present both methods separately. Based on the fact that the silicon oxide films are composed of Si-O bonds [16] and silicon nitride films are formed by $\mathrm{Si}-\mathrm{N}$ bonds [17], the correlation between BEMA volume fractions $\left(\mathrm{SiO}_{2}\right.$ and $\left.\mathrm{Si}_{3} \mathrm{~N}_{4}\right)$ of $\mathrm{SiO}_{\mathrm{x}} \mathrm{N}_{\mathrm{y}}$ layer with $\mathrm{Si}-\mathrm{O}$ and $\mathrm{Si}-\mathrm{N}$ concentrations bonds obtained from FTIR analysis can be investigated.

In this work, we investigated the optical and physico-chemical properties of LPCVD $\mathrm{SiO}_{\mathrm{x}} \mathrm{N}_{\mathrm{y}}$ layers deposited from nitrous oxide $\mathrm{N}_{2} \mathrm{O}$, ammonia $\mathrm{NH}_{3}$ and dichlorosilane $\mathrm{SiH}_{2} \mathrm{Cl}_{2}$. Firstly, the optical properties of silicon oxynitride layers were studied by spectroscopic ellipsometry (SE) using the Bruggeman effective medium approximation (BEMA) model. Secondly, Fourier-transform infrared spectroscopy (FTIR) was carried out to study the chemical bonding of the elaborated films. In order to improve the qualitative and quantitative analysis of $\mathrm{SiO}_{\mathrm{x}} \mathrm{N}_{\mathrm{y}}$ films composition, we performed the correlation between SE and FTIR analysis. Finally, the obtained stoichiometry of $\mathrm{SiO}_{\mathrm{x}} \mathrm{N}_{\mathrm{y}}$ films was used to study fully their chemical composition.

\section{Experimental details}

Silicon oxynitride $\left(\mathrm{SiO}_{\mathrm{x}} \mathrm{N}_{\mathrm{y}}\right)$ layers were deposited by low pressure chemical vapour deposition on single-crystal silicon wafer substrate from a mixture of dichlorosilane $\left(\mathrm{SiH}_{2} \mathrm{Cl}_{2}\right)$, nitrous oxide $\left(\mathrm{N}_{2} \mathrm{O}\right)$ and ammonia $\left(\mathrm{NH}_{3}\right)$. The deposition was carried out at temperature of $850^{\circ} \mathrm{C}$ during 50 minutes and a total pressure of 540 mTorr. The deposition duration was chosen constant in order to keep similar annealing conditions during the deposition processes. As a result, different thicknesses (typical values: $300-400 \mathrm{~nm}$ ) were obtained for the $\mathrm{SiO}_{\mathrm{x}} \mathrm{N}_{\mathrm{y}}$ films. Such high thicknesses allow to neglect any refractive index gradient occurring at the very beginning of the LPCVD process, and to finally insure the indepth homogeneity of the $\mathrm{SiO}_{x} \mathrm{~N}_{\mathrm{y}}$ films properties. The layers were elaborated with different values of relative gas flow ratio $\mathrm{r}=\mathrm{NH}_{3} / \mathrm{N}_{2} \mathrm{O}$ (the flow ratio changes from 0.03 to 0.23 ). The flow of $\left(\mathrm{N}_{2} \mathrm{O}+\mathrm{NH}_{3}\right)$ and $\mathrm{SiH}_{2} \mathrm{Cl}_{2}$ were kept constant at 160 and 200 standard cubic centimeters per minute $(\mathrm{sccm})$, respectively. The measured ellipsometric angles $\Delta$ and $\psi$ were 
obtained by a SpecEL2000-VIA spectroscopic ellipsometer with rotating analyzer in 450-900 $\mathrm{nm}$ wavelength range, at fixed incidence angle $\left(\Phi=70^{\circ}\right)$ for all measurements.

In order to study the evolution of films chemical composition, FTIR analysis was carried out using a Nicolet Avatar 360 spectrometer. The chemical bonds were determined by the localization of the absorption bands on a spectral region that extends between 400 and 4000 $\mathrm{cm}^{-1}$.

\section{Results and discussion}

\subsection{Optical properties}

The spectroscopic ellipsometry (SE) measurements have been used to estimate the refractive index and the $\mathrm{SiO}_{x} \mathrm{~N}_{\mathrm{y}}$ films thickness. This technique measures the complex ratio of the Fresnel reflection coefficients for parallel $\left(\mathrm{r}_{\mathrm{p}}\right)$ and perpendicular $\left(\mathrm{r}_{\mathrm{s}}\right)$ polarized light expressed as follows [10]:

$\rho=\frac{r_{p}}{r_{s}}=\tan \psi e^{i \Delta}$

Where $\Delta$ and $\psi$ are the measured ellipsometric angles.

However, the ellipsometric analysis is not done directly, it is necessary to model the structure of these heterogeneous materials to estimate the refractive index and $\mathrm{SiO}_{\mathrm{x}} \mathrm{N}_{\mathrm{y}}$ films thickness. Indeed, the ellipsometric analysis can be carried out from two methods depending on the nature of the materials studied: dispersion Models (Cauchy, Forouhi-Bloomer, Tauc-Lorentz, etc.) and Effective Medium Approximation theory (Bruggeman, Maxwell-Garnett). In this study, we chose the Bruggeman Effective Medium Approximation (BEMA) model because it is well suited to the heterogeneous materials [18]. In addition to their refractive index and thickness, the composition of the different layers can also be obtained by this model. This theory considers this material as a mixture of two homogeneous phases: silicon oxide $\left(\mathrm{SiO}_{2}\right)$ and silicon nitride $\left(\mathrm{Si}_{3} \mathrm{~N}_{4}\right)$. It is valid in the visible (VIS) and near infrared (IR) [14]. The effective refractive index has been defined as $[8,13]$ :

$f_{\mathrm{SiO}_{2}} \frac{n_{\mathrm{SiO}_{2}}^{2}-n^{2}}{n_{\mathrm{SiO}_{2}}^{2}+2 n^{2}}+f_{\mathrm{Si}_{3} N_{4}} \frac{n_{\mathrm{Si}_{3} N_{4}}^{2}-n^{2}}{n_{\mathrm{Si}_{3} N_{4}}^{2}+2 n^{2}}$

$f_{\mathrm{SiO}_{2}}+f_{\mathrm{Si}_{3} \mathrm{~N}_{4}}=1$

where $f_{\mathrm{SiO}_{2}}$ and $f_{\mathrm{Si}_{3} \mathrm{~N}_{4}}$ are the relative volume fraction of $\mathrm{SiO}_{2}$ and $\mathrm{Si}_{3} \mathrm{~N}_{4}$, respectively in the

film, $n_{\mathrm{SiO}_{2}}$ and $n_{\mathrm{Si}_{3} \mathrm{~N}_{4}}$ represents the refractive index of $\mathrm{SiO}_{2}$ and $\mathrm{Si}_{3} \mathrm{~N}_{4}$, respectively (the refractive index for $\mathrm{SiO}_{2}$ and $\mathrm{Si}_{3} \mathrm{~N}_{4}$ were obtained using Palik's data [19]).

The refractive index, layers thickness and volume fractions were deduced by optimization of the ellipsometric measurements $\cos \Delta$ and $\tan \psi$. The calculated theoretical profiles based on 
the Bruggeman model were compared to experimental spectra obtained from ellipsometric data using the mean squares error (MSE) defined as:

$$
\chi^{2}=\frac{1}{N} \sum_{i=1}^{N}\left[\left(\tan \psi_{\exp }-\tan \psi_{t h}\right)^{2}+\left(\cos \Delta_{\exp }-\cos \Delta_{t h}\right)^{2}\right]
$$

where $\mathrm{N}$ is the number of total measurements, $\cos \Delta_{\exp }$ and $\tan \psi \exp$ are the experimental data and $\cos \Delta_{\text {th }}$ and $\tan \psi$ th are the calculated data.

The fitting quality of experimental and theoretical data is controlled by MSE. The superposition of experimental and theoretical spectra ( $\cos \Delta, \tan \psi$ as a function of wavelength) presented in Figure 1 showed a good agreement, that permits the deduction of the refractive index and the different volume fractions, as well as the estimation of films thicknesses. All obtained results are summarized in the Table 1.

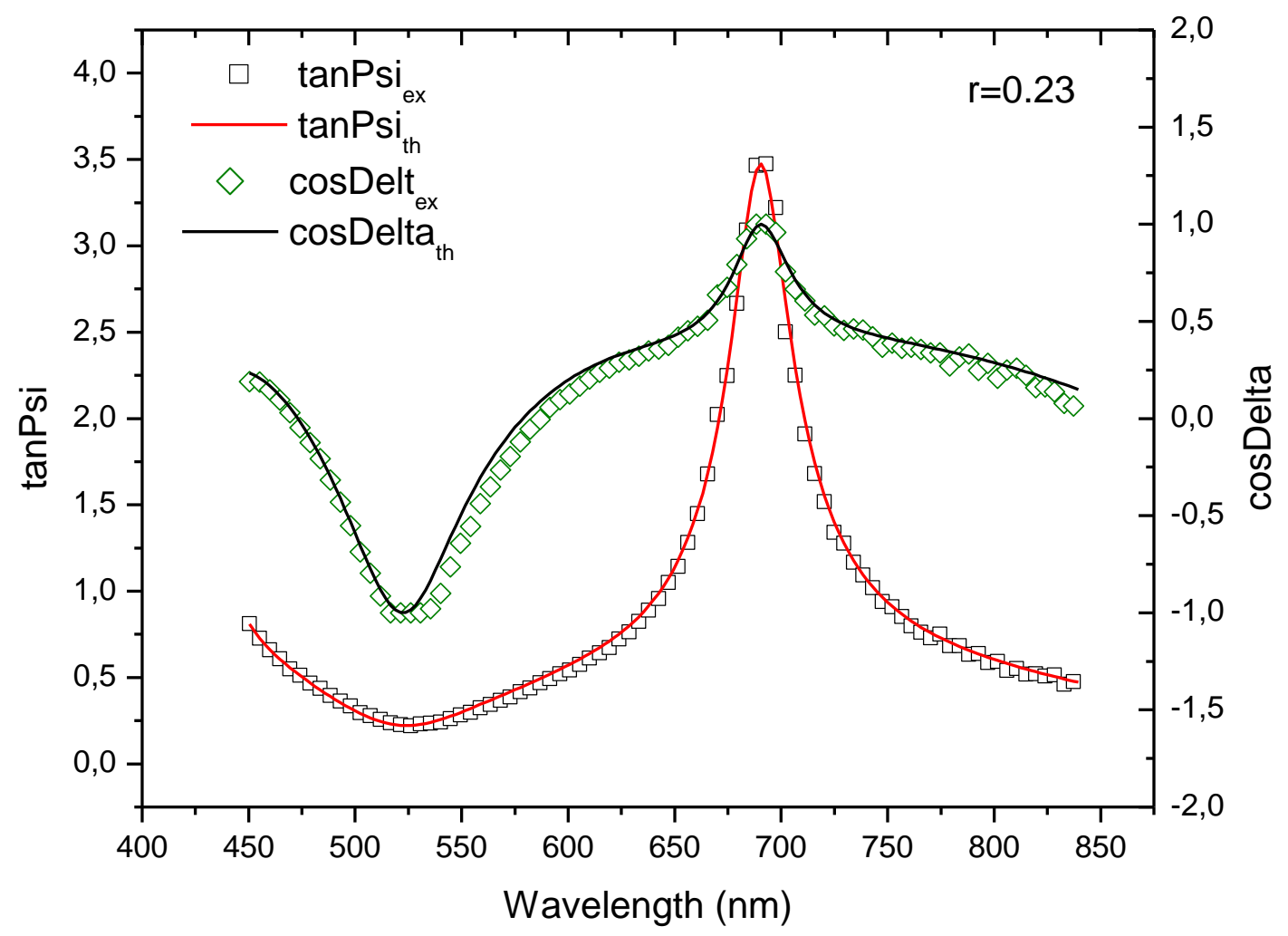

Fig. 1. Comparison between measured (cosDelta $\left.a_{\mathrm{ex}}, \operatorname{tanPsi}_{\mathrm{ex}}\right)$ and calculated (cosDelta $\left.\mathrm{th}_{\mathrm{th}}, \tan P \mathrm{si}_{\mathrm{th}}\right)$ spectra of $\tan \psi$ and $\cos \Delta$ for $\mathrm{LPCVD} \mathrm{SiO}_{\mathrm{x}} \mathrm{N}_{\mathrm{y}}$ films obtained with $\mathrm{r}=0.23$. 
Table 1. Estimated refractive index, volume fraction, thickness and mean square errors according to BEMA model

\begin{tabular}{ccccccc}
\hline Sample & $\mathrm{r}=\mathrm{NH}_{3} / \mathrm{N}_{2} \mathrm{O}$ & $\mathrm{n}($ at $830 \mathrm{~nm})$ & $\mathrm{f}(\%) \mathrm{SiO}_{2}$ & $\mathrm{f}(\%) \mathrm{Si}_{3} \mathrm{~N}_{4}$ & Thickness(nm) & MSE \\
\hline $\mathrm{S} 1$ & 0.03 & 1.45 & 98.2 & 1.8 & 285 & 0,0024 \\
$\mathrm{~S} 2$ & 0.07 & 1.52 & 86.5 & 13.5 & 325 & 0,0175 \\
$\mathrm{~S} 3$ & 0.08 & 1.53 & 85.5 & 14.5 & 345 & 0,0130 \\
$\mathrm{~S} 4$ & 0.14 & 1.55 & 81.3 & 18.7 & 360 & 0,0065 \\
$\mathrm{~S} 5$ & 0.23 & 1.60 & 73.5 & 26.5 & 400 & 0,0037 \\
\hline
\end{tabular}

The Bruggeman EMA model assumes that $\mathrm{SiO}_{\mathrm{x}} \mathrm{N}_{\mathrm{y}}$ films are formed by two distinct phases $\mathrm{SiO}_{2}$ and $\mathrm{Si}_{3} \mathrm{~N}_{4}$. As seen in Table 1, the refractive index, the volume fractions $\left(\mathrm{SiO}_{2}\right.$ and $\mathrm{Si}_{3} \mathrm{~N}_{4}$ ) and films thickness change according to the relative gas flow ratio $r=\mathrm{NH}_{3} / \mathrm{N}_{2} \mathrm{O}$. We can see that the refractive index of $\mathrm{LPCVD} \mathrm{SiO}_{x} \mathrm{~N}_{\mathrm{y}}$ films increase from 1.45 to 1.60 by adding $\mathrm{NH}_{3}$ and reducing the $\mathrm{N}_{2} \mathrm{O}$ gas flow ratio. This increase can be attributed to the incorporation of nitrogen atoms in the films. In other words, the refractive index of $\mathrm{SiO}_{\mathrm{x}} \mathrm{N}_{\mathrm{y}}$ thin films can be controlled through variations of the precursor gases. Therefore, when the flow rates of $\mathrm{NH}_{3}$ and $\mathrm{N}_{2} \mathrm{O}$ varies, the nitrogen and oxygen contents in silicon oxynitride change. The extinction coefficient $(\mathrm{k})$ of our silicon oxynitride layers remains lower than $10^{-6}$ for wavelengths above $450 \mathrm{~nm}$. The obtained SE analysis results and the established model are in good agreement with previously works reported in the literature [7,10,20].

\subsection{Physico-chemical properties}

Figure 2 shows FTIR absorption spectra of $\mathrm{SiO}_{x} \mathrm{~N}_{\mathrm{y}}$ films deposited at different $\mathrm{NH}_{3} / \mathrm{N}_{2} \mathrm{O}$ flow ratio. The main absorption band was observed in the $600-1300 \mathrm{~cm}^{-1}$ region. This band has also been identified as $\mathrm{Si}-\mathrm{O}$ and $\mathrm{Si}-\mathrm{N}$ bonds assigned to different vibration modes [7,21,22]. Moreover, the FTIR spectra also show another absorption band of Si-O bonds assigned to rocking mode located at approximately $450 \mathrm{~cm}^{-1}$ [23]. It is observed that the FTIR spectra of $\mathrm{SiO}_{x} \mathrm{~N}_{y}$ films do not have hydrogen bonds $\mathrm{Si}-\mathrm{H}$ and $\mathrm{N}-\mathrm{H}$. This absence is related to the presence of an oxidizing gas in the gas phase: nitrous oxide (whose flow varies between 130 and $155 \mathrm{sccm})$. The oxygen atoms have a tendency to preferentially bind with the silicon atoms [24]. This phenomenon is further enhanced by the high contents of oxygen, i.e. low contents of nitrogen, in the $\mathrm{SiO}_{x} \mathrm{~N}_{\mathrm{y}}$ films and thus their high number of $\mathrm{Si}-\mathrm{O}$ bonds. On the other hand, the high deposition temperature $\left(850^{\circ} \mathrm{C}\right)$ in our case is another factor that can influence the lack of hydrogen incorporation in $\mathrm{SiO}_{\mathrm{x}} \mathrm{N}_{\mathrm{y}}$ films. These observations were also reported by Kapoor et al: they showed that the amount of Si-H and N-H drastically decreased as the deposition temperature increased beyond $600^{\circ} \mathrm{C}[25]$.

We found that the increase of gas flow ratio $\left(r=\mathrm{NH}_{3} / \mathrm{N}_{2} \mathrm{O}\right)$ affects the $\mathrm{SiO}_{\mathrm{x}} \mathrm{N}_{\mathrm{y}}$ films FTIR spectra by the apparition of a shoulder with a shift of the main peak towards lower wavenumbers values. This behaviour is explained by an increase of the nitrogen incorporation in the films and therefore an enhancement of the $\mathrm{Si}-\mathrm{N}$ bonds. In order to obtain qualitative information on the vibration modes of $\mathrm{Si}-\mathrm{N}$ and $\mathrm{Si}-\mathrm{O}$ bonds, we have carried out a deconvolution of the main absorption bonds into multiple Gaussian peaks. 


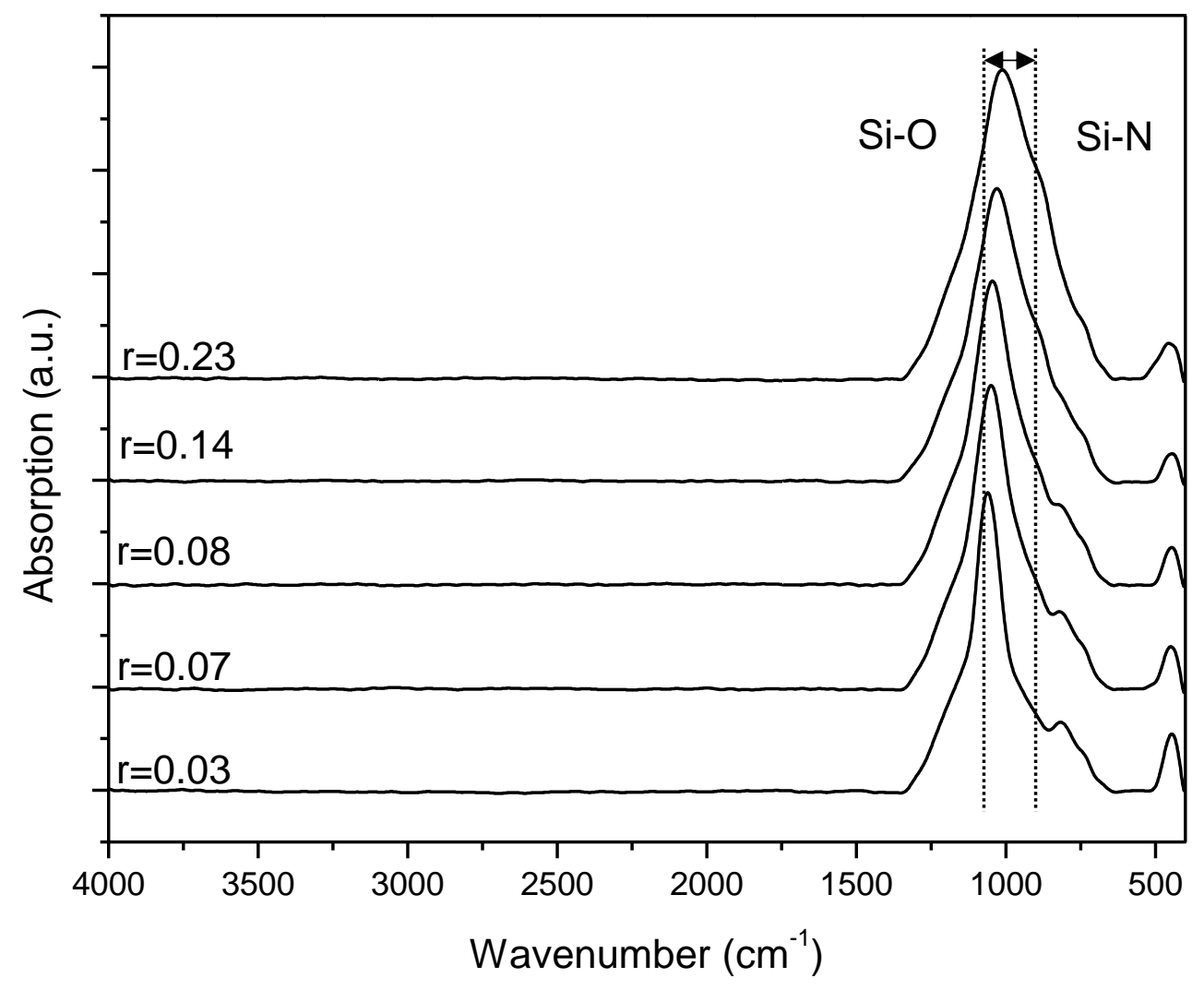

Fig. 2. FTIR absorption spectra of $\mathrm{SiO}_{\mathrm{x}} \mathrm{N}_{\mathrm{y}}$ films.

After the deduction of the integrated area calculated by the conventional deconvolution of the predominant absorption band, four Gaussian peaks were deduced (see Fig. 3). These peaks are associated to the symmetric stretching, asymmetric stretching and bending vibration modes of $\mathrm{Si}-\mathrm{O}$ bonds and stretching mode of Si-N bonds [9,23] located at around 1030, 1170, 800 and $890 \mathrm{~cm}^{-1}$, respectively. However, the difficulty arises in the correct estimation of the area, the full width at half maximum (FWHM) of the peaks and their locations obtained by deconvolution. In order to improve this analysis for $\mathrm{LPCVD} \mathrm{SiO}_{x} \mathrm{~N}_{\mathrm{y}}$ films, we propose in this work a method based on the correlation between ellipsometric and FTIR measurements. According to the fact that the density of $\mathrm{Si}-\mathrm{N}$ bonds is related to the mass density of silicon nitride [3], we can establish a relationship between the Si-N bonds density described by the integrated area of the deconvoluted peak and the calculated $\mathrm{Si}_{3} \mathrm{~N}_{4}$ volume fraction from BEMA model. Thus, the new integrated area $A_{S i-N}$, or in other words, the normalized area of the peak related to $\mathrm{Si}-\mathrm{N}$ bonds can be expressed as follows: 
$A_{S i-N}=\frac{A_{m p} \cdot f_{S i_{3} N_{4}}}{100}$

Where $A_{m p}$ is the integrated area obtained by deconvolution of the main peak and $f_{s i_{3} N_{4}}$ is the volume fraction of silicon nitride.

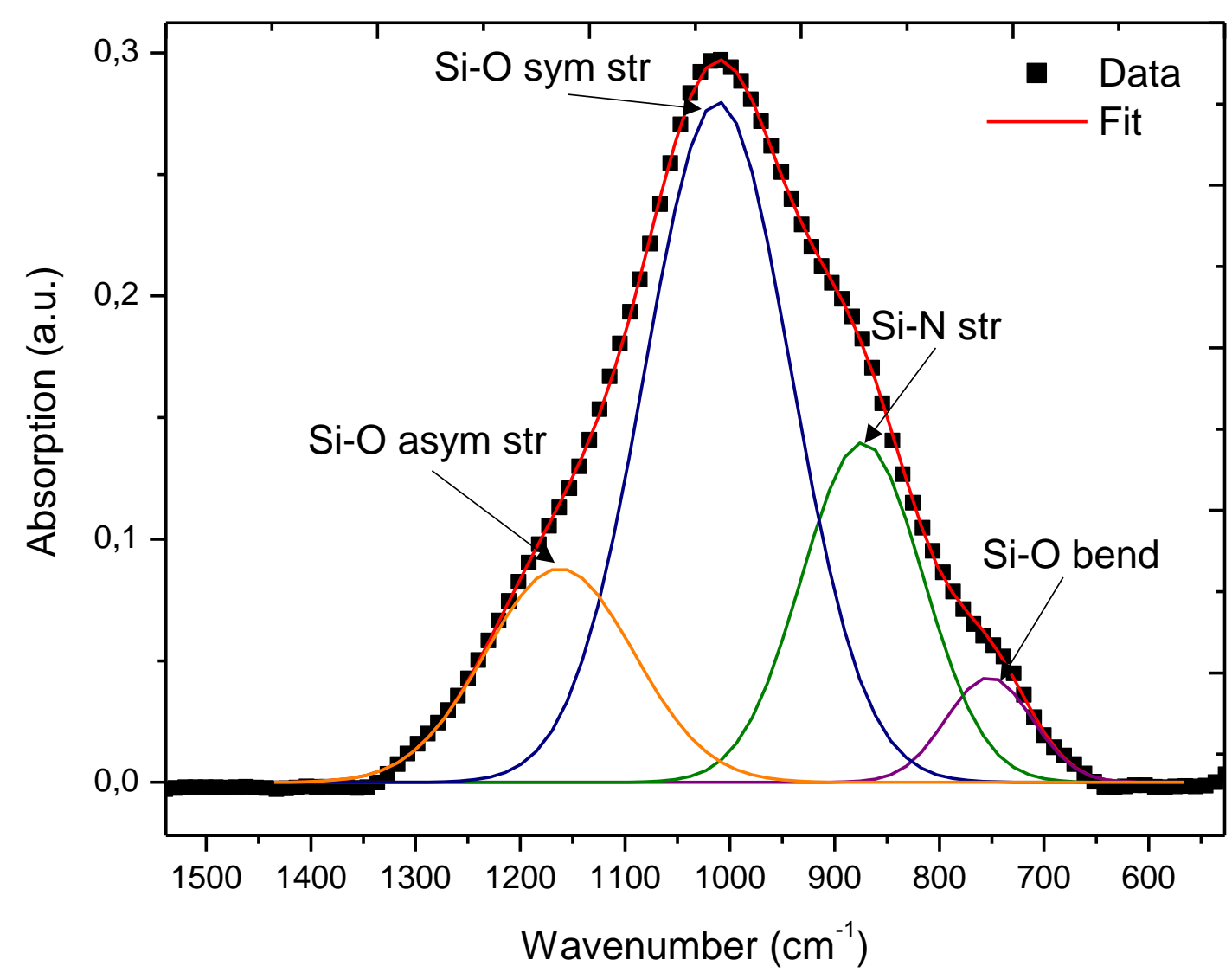

Fig. 3. Deconvolution of the main peak for the film obtained with $r=0.23$. 
Table 2. Si-N absorption band area and Full Width at Half Maximum (FWHM) obtained by conventional deconvolution (case 1) and by correlation FTIR-BEMA (case 2).

\begin{tabular}{|c|c|c|c|c|c|}
\hline \multirow{2}{*}{ Sample } & \multirow{2}{*}{$\begin{array}{c}\mathrm{r}= \\
\mathrm{NH}_{3} / \mathrm{N}_{2} \mathrm{O}\end{array}$} & \multicolumn{2}{|c|}{ Area } & \multicolumn{2}{|c|}{ FWHM $\left(\mathrm{cm}^{-1}\right)$} \\
\hline & & Case 1 & Case 2 & Case 1 & Case 2 \\
\hline $\mathrm{S} 1$ & 0.03 & 17 & 1 & 137 & 61 \\
\hline S2 & 0.07 & 15 & 10 & 109 & 87 \\
\hline S3 & 0.08 & 21 & 11 & 133 & 93 \\
\hline S4 & 0.14 & 17 & 15 & 114 & 106 \\
\hline S5 & 0.23 & 20 & 24 & 115 & 122 \\
\hline
\end{tabular}

As can be seen from Table 2, the conventional deconvolution method does not give significant results. However, for the proposed method (case 2), it is found that there is an increase in the Si-N absorption band area and the full width at half-height FWHM. The increase of these two parameters (area and FWHM) is in good correlation with the increase of nitrogen amount in the films due to the rate $r$ increase, as illustrated in Figure 4 and Table 2. This behavior can be explained by the increase in the films density that is also confirmed by the increase of the refractive index values previously obtained by SE. 


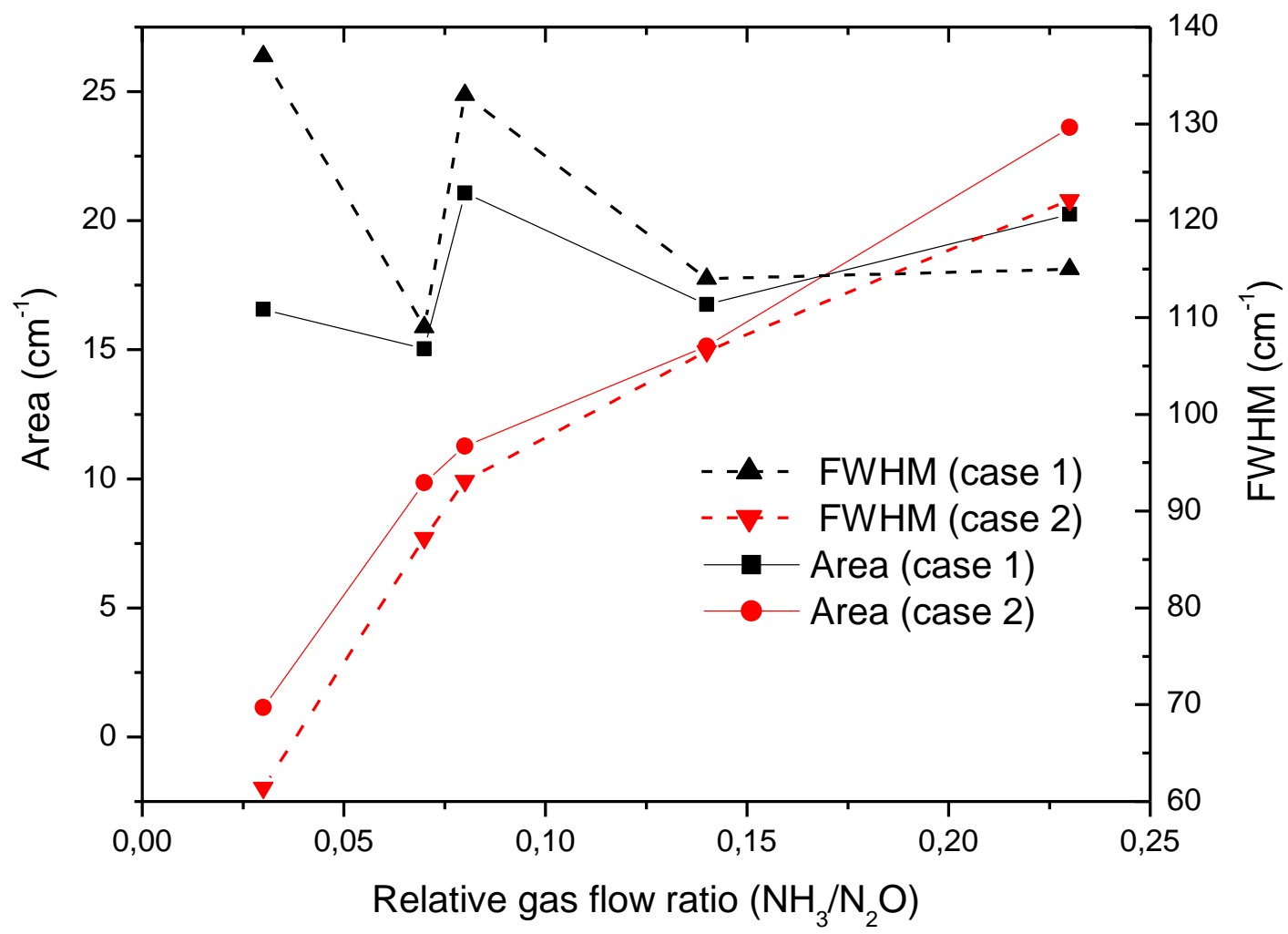

Fig. 4. Evolution of the Si-N absoption band area A and FWHM obtained by the conventionnal deconvolution (case 1) and the deconvolution based on the correlation between FTIR and BEMA model (case 2) as fonction of the relative gas flow ratio.

Details of the peak positions obtained by deconvolution thanks to the proposed method of the main absorption band are summarized in Table 3. We found that the obtained infrared peak positions are in good agreement with previous studies on $\mathrm{SiO}_{\mathrm{x}} \mathrm{N}_{\mathrm{y}}$ layers [3,9]. As seen in Table 3, all peaks position shifts with increasing relative gas flow ratio $\mathrm{r}$. The Si-N peak position assigned to the stretching vibration mode shifts towards lower wavenumbers (from $949 \mathrm{~cm}^{-1}$ for $\mathrm{r}=0.03$ to $879 \mathrm{~cm}^{-1}$ for $\mathrm{r}=0.23$ ). On the other hand, the Si-O peak position attributed to the symmetric stretching vibration shifts also to the low wavenumbers values $\left(1056-1010 \mathrm{~cm}^{-1}\right)$. These peaks position evolution are due to the increase of the nitrogen amount and the reduction of oxygen in $\mathrm{SiO}_{\mathrm{x}} \mathrm{N}_{\mathrm{y}}$ films.

Table 3. LPCVD $\mathrm{SiO}_{\mathrm{x}} \mathrm{N}_{\mathrm{y}}$ infrared vibrations modes deduced by the deconvolution based on the correlation between FTIR spectra and BEMA model.

\begin{tabular}{|c|c|c|c|c|c|}
\hline \multirow{2}{*}{ Vibration mode } & \multicolumn{5}{|c|}{ Peak position $\left(\mathrm{cm}^{-1}\right)$} \\
\hline & $\mathrm{S} 1$ & $\mathrm{~S} 2$ & $\mathrm{~S} 3$ & $\mathrm{~S} 4$ & S5 \\
\hline Si-N stretching & 949 & 933 & 926 & 895 & 879 \\
\hline
\end{tabular}


Si-O symmetric str.

Si-O asymmetric str.
1056

1075

820
1047

1177

815
1042

1026

1010

Si-O bending

779

750

It has been reported that the stoichiometry of these films can be estimated using the relation between the atomic and the bond concentrations [26]:

$$
\begin{aligned}
& x=\frac{[O]}{[S i]}=\frac{2[S i-O]}{[S i-O]+[S i-N]} \\
& y=\frac{[N]}{[S i]}=\frac{4}{3} \frac{[S i-N]}{[S i-O]+[S i-N]}
\end{aligned}
$$

The absolute concentrations of $[\mathrm{Si}-\mathrm{O}]$ and $[\mathrm{Si}-\mathrm{N}]$ bonds in the films were calculated by the following equation $[26,27]$ :

$$
[S i-X]=K_{S i-X} \int_{v} \frac{\alpha(\omega)}{\omega} d \omega=K_{S i-X} A_{S i-X}
$$

where $[\mathrm{Si}-\mathrm{X}]$ is the concentration of the $\mathrm{Si}-\mathrm{X}$ bond, $\alpha(\omega)$ is the absorption coefficient at the frequency $\omega, \mathrm{K}_{\mathrm{Si}-\mathrm{X}}$ and $\mathrm{ASi}-\mathrm{X}$ are the calibration factor and the integrated area of the $\mathrm{Si}-\mathrm{X}$ absorption bands, respectively. $\mathrm{K}_{\mathrm{Si}-\mathrm{O}}$ and $\mathrm{K}_{\mathrm{Si}-\mathrm{N}}$ were estimated at $1.510^{19} \mathrm{~cm}^{-2}$ [28] and 2.1 $10^{19} \mathrm{~cm}^{-2}$ [27].

To examine the validity of the composition data ( $\mathrm{x}$ and $\mathrm{y}$ ) using the proposed method of deconvolution, we have compared these results with two other methods. The first method is based on the measurement of $[\mathrm{O}],[\mathrm{N}]$ and [Si] atomic concentrations with RBS technique. The second method is an indirect estimation of the stoichiometry of $\mathrm{SiO}_{\mathrm{x}} \mathrm{N}_{\mathrm{y}}$ films from its refractive index value (n) at $830 \mathrm{~nm}$ [8]. Indeed, considering a $\mathrm{SiO}_{2} / \mathrm{Si}_{3} \mathrm{~N}_{4}$ heterogeneous medium in the frame of the BEMA model, Hajji et al. established an attractive equation to calculate the values of $\mathrm{x}$ and $\mathrm{y}$ of $\mathrm{SiO}_{\mathrm{x}} \mathrm{N}_{\mathrm{y}}$ films with an error lower than $2 \%$ :

$n=2-0.41 x+0.07 x^{2}=1.45+0.19 y+0.16 y^{2}$

As shown in Figure 5 and 6, the agreement between the values obtained from the calculated concentration of $[\mathrm{Si}-\mathrm{O}]$ and $[\mathrm{Si}-\mathrm{N}]$ bonds and those estimated by the BEMA method is quite satisfactory, since the discrepancies between the $x$ values of these methods are less than $6 \%$. However, this discrepancy becomes more important for values of y (less than 20\%). This may be related to the dependence of the calculated values with the calibration factors (KSi-N and $\mathrm{K}_{\mathrm{Si}-\mathrm{O}}$ ). In order to optimize the values of the calibration factors, we have fitted the obtained 
data from Hajji et al. formula (eq. (9)), as shown in Figures 5 and 6. The obtained values are $\mathrm{K}_{\mathrm{Si}-\mathrm{O}}=1,310^{19}$ and $\mathrm{K}_{\mathrm{Si}-\mathrm{N}}=2,310^{19}$. Moreover, the composition indices of $\mathrm{SiO}_{\mathrm{x}} \mathrm{N}_{\mathrm{y}}$ films (x and y) obtained by this method respond very well to the relationship $2 x+3 y=4$ [29]. Thus, the calculated of the integrated area of the absorption bands using the proposed method can be lead to the correct estimation of the stoichiometry of $\mathrm{SiO}_{\mathrm{x}} \mathrm{N}_{\mathrm{y}}$ films. We can see (Fig. 5 and 6) that the atomic ratio $\mathrm{x}$ decreases from 1.94 to 1.26 and y increases from 0.04 to 0.49 with increasing relative gas flow ratio. This change in the films composition can be related to the replacement of the oxygen atoms by nitrogen ones in films bonding structures. This result is confirmed by the refractive index values obtained by SE measurements, which varies between 1.45 and 1.60 in our films.

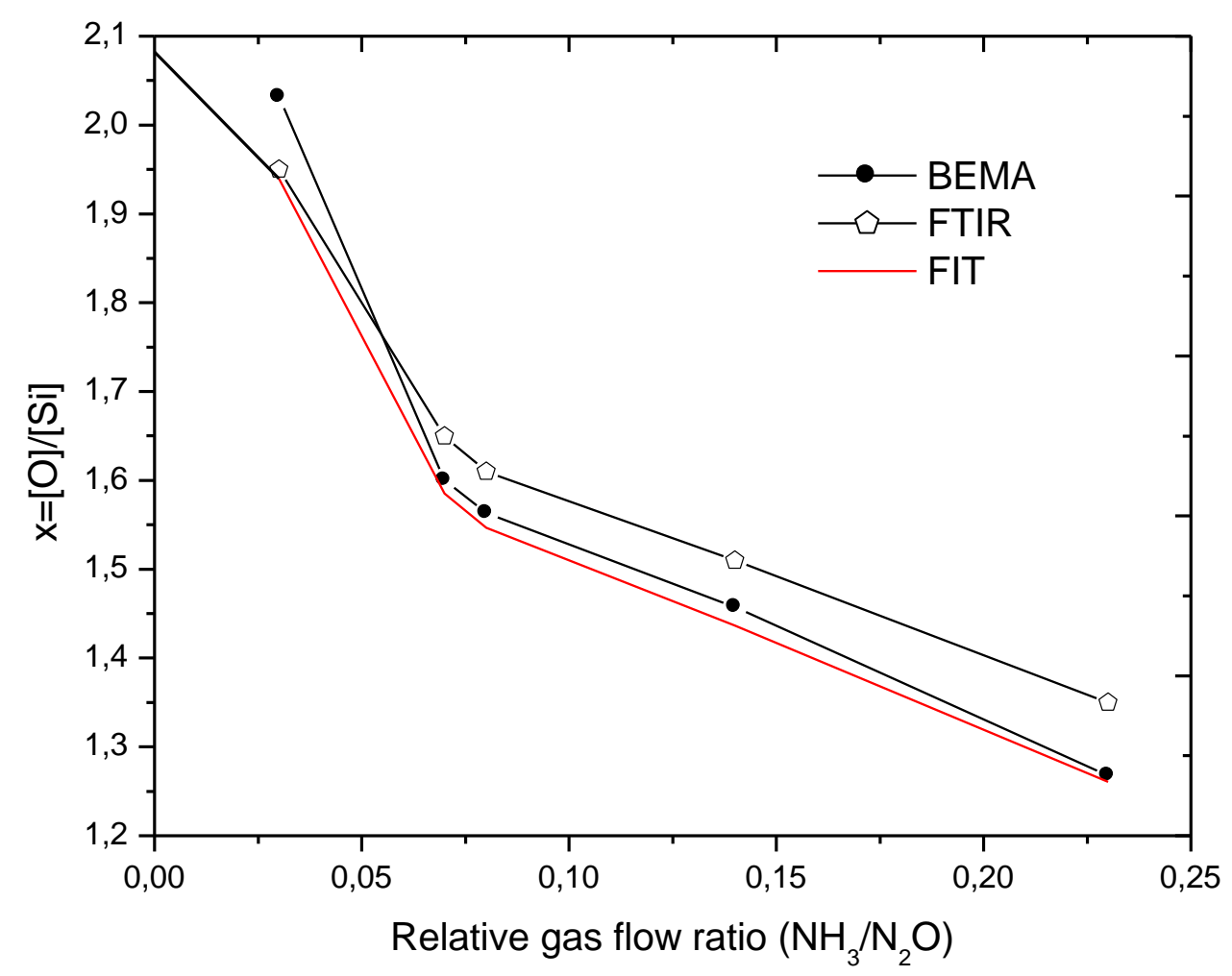

Fig. 5. $[\mathrm{O}] /[\mathrm{Si}]$ atomic ratio (x) obtained from BEMA method (using eq. (9)) and FTIR analysis (using the proposed deconvolution method). 


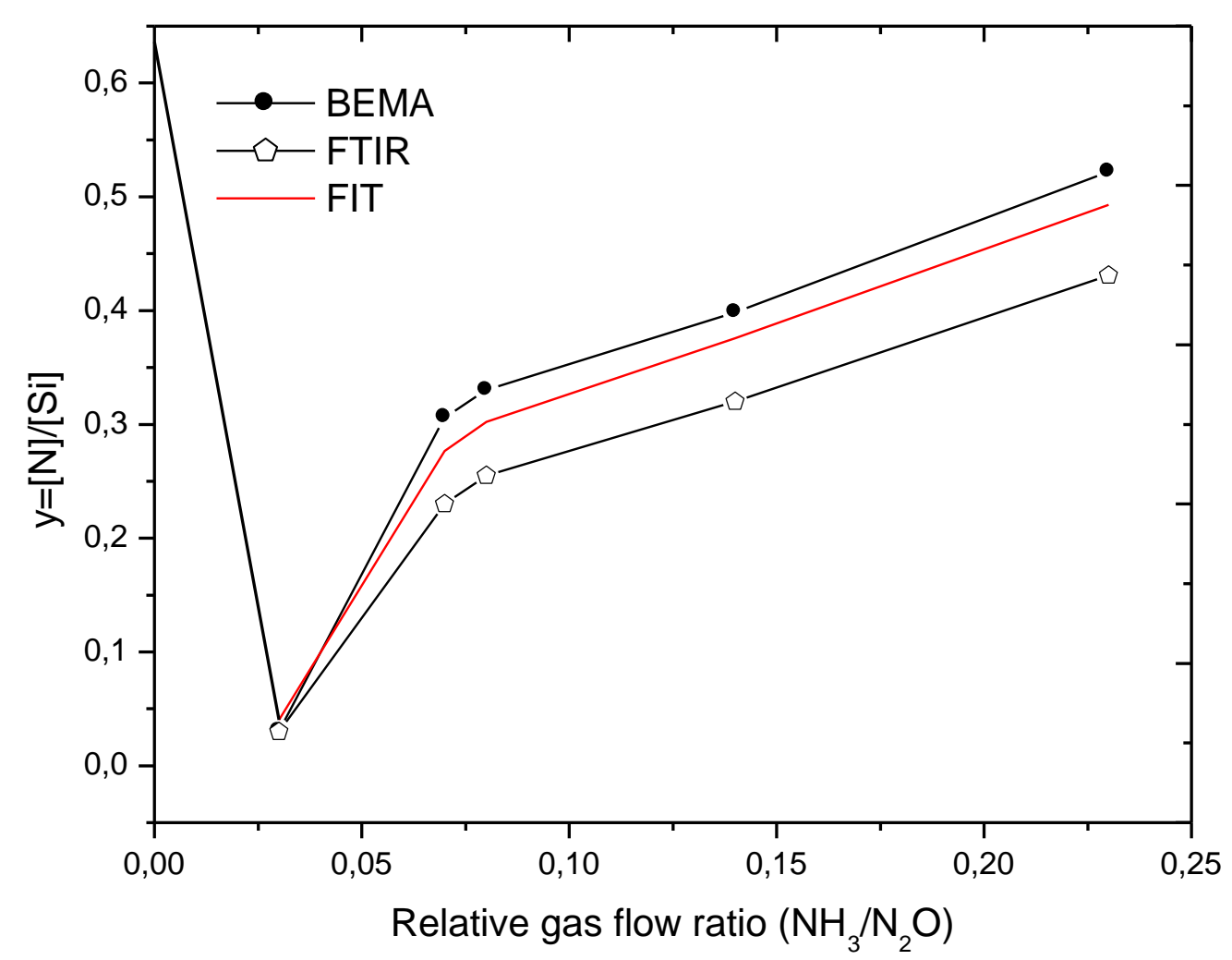

Fig. 6. $[\mathrm{N}] /[\mathrm{Si}]$ atomic ratio (y) obtained from BEMA method (using eq. (9)) and FTIR analysis (using the proposed deconvolution method).

\section{Conclusion}

The $\mathrm{SiO}_{\mathrm{x}} \mathrm{N}_{\mathrm{y}}$ films were deposited by LPCVD using different values of the relative gas flow ratio $\left(\mathrm{NH}_{3} / \mathrm{N}_{2} \mathrm{O}\right)$. The optical and physico-chemical properties have been investigated with $\mathrm{SE}$ and FTIR methods. The films thickness, refractive index and volume fractions of $\mathrm{SiO}_{2}$ and $\mathrm{Si}_{3} \mathrm{~N}_{4}$ have been estimated by comparing the SE measurements and calculated data from Bruggeman EMA model. It has been found that the increase of refractive index of $\mathrm{SiO}_{\mathrm{x}} \mathrm{N}_{\mathrm{y}}$ films is related to the quantity of nitrogen introduced into films. The FTIR analysis also showed that the incorporation of nitrogen atoms leads to the change of the Si-O and Si-N bonds intensity. The correlation between SE and FTIR analysis helped us to estimate the area of absorption bands, the FWHM and the peaks position of the Si-O and Si-N vibrational modes. The peaks position was found to shift when the chemical environment is modified. Finally, the stoichiometry of $\mathrm{SiO}_{\mathrm{x}} \mathrm{N}_{\mathrm{y}}$ films was estimated from the calculated area using the proposed deconvolution method. The comparison of our results with those estimated by the BEMA method proved the proposed method and their validity. On the other hand, the results were also verified using the relation $2 x+3 y=4$. The obtained results of the films composition confirmed that the increase of the relative gas flow ratio causes the decrease of oxygen amount and the increase of nitrogen in the $\mathrm{SiO}_{\mathrm{x}} \mathrm{N}_{\mathrm{y}}$ films. 


\section{References}

1. N. Brinkmann, D. Sommer, G. Micard, G. Hahn, B. Terheiden, Solar. Ener. Mat. \& Solar Cells. 108, 180 (2013)

2. Y. Nakanishi, K. Kato, H. Omoto, T. Tomioka, A. Takamatsu, Thin. Sol. Films. 520, 3862 (2012)

3. B. Hallamn, B. Tjahjono, S. Wenham, Solar. Ener. Mat. \& Solar. Cells. 96, 173 (2012)

4. V. Godinho, V.N. Denisov, B.N. Mavrin , N.N. Novikova, E.A. Vinogradov, V.A. Yakovlev, C. Fernández-Ramos, M.C. Jiménez de Haro, A. Fernández, Appl. Surf. Sci. 256, 156 (2009)

5. E. Halova, S. Alexandrova, A. Szekeres, M. Modreanu, Micro. Rel. 45, 982 (2005)

6. H.Y. Choi, H. Wong, V. Filip, B. Sen, C.W. Kok, M. Chan, M.C. Poon, Thin. Sol. Films 504, 7 (2006)

7. J. Dupuis, E. Fourmond, D. Ballutaud, N. Bererd, M. Lemiti, Thin. Sol. Films. 519, 1325 (2010)

8. B. Hajji, P. Temple-Boyer, F. Olivie, A. Martinez, Thin. Sol. Films. 354, 9 (1999)

9. S-K. Sharmaa, S. Barthwal, V.Singhd, A. Kumare, K. Prabhat, K. Dwivedi, B. Prasadg, D. Kumarg, Micron. 44, 339 (2013)

10. S.H. Mohamed, Physica B. 406, 211 (2011)

11. D.E. Aspnes. Thin. Sol. Films. 89, 249 (1982)

12. P. Temple-Boyer, B. Hajji, J.L. Alay, J.R. Morante, A. Martinez, Sensors Actua. 74, 52 (1999)

13. R. Radoi, C. Gherasim, M. Dinescu, J, Alloys Comp. 286, 309 (1999)

14. J. Rivory, Thin Solid Films. 313-314, 333 (1998)

15. A.M. Hartel, D. Hiller, S. Gutsch, P. Löper, S. Estradé, F. Peiró, B. Garrido, M. Zacharias, Thin. Sol. Films. 520, 121 (2011)

16. A. Morales, J. Barretoa, C. Domınguez, M. Rieraa, M. Aceves, J. Carrilloc, Physica E. 38, 54(2007)

17. L.S. Patil, R.K. Pandey, Jaspal P. Bange, S.A. Gaikwad, D.K. Gautam. Opt .Materials, 27. 663(2005)

18. S. Bosch, J. Ferré-Borrull, N. Leinfellner, A. Canillas, Surf. Sci. 453, 9 (2000) 
19. E. D. Palik, Handbook of Optical Constants of Solids (Academic press 1998)

20. A. Szekeres, S. Alexandrova, M. Modreanu, P. Cosmin, M. Gartner, Vacuum. 61, 205 (2001)

21. J. Dupuis, E. Fourmond , J.F. Lelièvre, D. Ballutaud, M. Lemiti, Thin. Sol. Films. 516, 6954 (2008)

22. J-H. Liao, J-Y. Hsieh, H-J. Lin, W-Y. Tang, C-L. Chiang, Y-S. Lo, T-B. Wu, L-W. Yang, T. Yang, K-C. Chen, C-Y. Lu, J. Phys. D: Appl. Phys. 42, 175102 (2009)

23. M. Bedjaoui, B. Despax, Thin. Sol. Films. 518, 4142 (2010)

24. M.I. Alayo, D. Criado, L.C.D. Gonçalves, I. Pereyra, J. Non-Crystalline. Sol. 338-340 76 (2004)

25. Vik J. Kapoor, Ray A. Tun, Dan Xu, Robert S. Bailey. IEEE. Trans. Comp. Pack. Man. Technology, 17. 367 (1994)

26. J.C. Rostaing, Y. Cros, S.C. Gujrathi, S. Poulain, J. Non-Crystalline. Sol. 97\&98, 1051 (1987)

27. E. Bustarret, M. Bensouda, M. C. Habrard, J.C. Bruyere, Phys. Rev B. 38, 8171 (1988)

28. M. Zacharias, T. Driisedau, A. Panckow, H. Freistedt, B. Garke, J. Non-Crystalline Sol. 169, 29 (1994)

29. W. Bohne, J.Röhrich, A. Schöpke, B. Selle, I. Sieber, W. Fuhs,A. del Prado, E. San Andrés, I.Mártil, G. González-Díaz, Nucl. Instruments Meth. Phys. Res B. 217, 237 (2004) 